\title{
Environmental persistence but not per capita transmission rates of a chytrid fungus
} determines infection prevalence

Samantha L. Rumschlag, ${ }^{\mathrm{a}, \mathrm{b},}$, Sadie A. Roth ${ }^{\mathrm{b}, \mathrm{c}}$, Taegan A. McMahon ${ }^{\mathrm{d}, \mathrm{e}}$, Jason R. Rohra,b, David J.

17 Author Contributions: S.L.R, T.A.M., D.J.C., and J.R.R designed the experiment; S.A.R. and

18 S.L.R conducted the experiments; T.A.M. completed the qPCR analyses; S.L.R. and D.J.C.

19 analyzed the data; S.L.R. wrote the manuscript; T.A.M, D.J.C, and J.R.R. provided funding, and

20 all authors contributed to editing the manuscript.

22 Data Availability: Data will be made available via figshare upon acceptance of the publication. 
ABSTRACT

25 Understanding local-scale variability in disease dynamics can be important for informing

26 strategies for surveillance and management. For example, the amphibian chytrid fungus

27 (Batrachochytrium dendrobatidis; $\mathrm{Bd}$ ), which is implicated in population declines and species

28 extinctions of amphibians, causes spatially variable epizootics and extirpations of its hosts.

29 Outbreak heterogeneity could be driven by differential survival of zoospores, the free-living

30 infectious life stage of $\mathrm{Bd}$, or the persistence of dead zoospores and/or its metabolites in water,

31 which could induce resistance among hosts. To gain a mechanistic understanding of the potential

32 for variation in local transmission dynamics of $\mathrm{Bd}$, we conducted $\mathrm{Bd}$ survival and infection

33 experiments and then fit models to discern how Bd mortality, decomposition, and per-capita

34 transmission rate vary among water sources. We found that infection prevalence differed among

35 water sources, which was driven by differences in mortality rates of Bd zoospores, rather than

36 differences in per-capita transmission rates. Specifically, zoospore mortality rates varied

37 significantly among pond water treatments and were lower in artificial spring water compared to

38 pond water sources. These results suggest that variation in Bd infection dynamics could be a

39 function of differences in exposure of hosts to live $\mathrm{Bd}$. In contrast to the persistence of live

40 zoospores, we found that rates of decomposition of dead zoospores did not vary among water

41 sources. These results may suggest that exposure of hosts to dead $\mathrm{Bd}$ or its metabolites, which

42 have been shown to induce acquired resistance, might not commonly vary among nearby sites.

43 Ultimately, a mechanistic understanding of the drivers of variable epizootics of Bd could lead to

44 increases in the effectiveness of surveillance and management strategies.

45 Key words: Batrachochytrium dendrobatidis, pathogen mortality, pathogen decomposition,

46 transmission, amphibians, host-pathogen dynamics 
Strategies for the surveillance and management of wildlife infectious diseases are

49 informed by a mechanistic understanding of the distribution and persistence of pathogens in host

50 populations and the environment (Cunningham et al. 2017, Barnett and Civitello 2020). Yet,

51 characterizing these mechanisms remains immensely challenging because of the complexity and

52 natural variability of host-pathogen systems and the environments in which they exist (Plowright

53 et al. 2008, Tompkins et al. 2011, Gandon et al. 2016). For instance, infection prevalence can

54 vary widely among neighboring host populations (Ostfeld et al. 2005, Favier et al. 2005, Wood

et al. 2007, Munster et al. 2007). Some of this local variability may be a function of the net

effects of environmental conditions on host exposure to pathogens and host susceptibility to

infection (Rohr et al. 2008a, Civitello et al. 2013, Civitello and Rohr 2014, Rumschlag et al.

2019). Spatial variation in environmental conditions may influence mortality of infectious, free-

living pathogens, leading to differences in host exposure. For instance, the survival of free-living

61 leads to spatial variability in their abundance in intertidal zones (Koprivnikar et al. 2010, Lei and

62 Poulin 2011). At the same time, environmental variability could lead to differences in

63 transmission of pathogens through effects on host susceptibility to infections. For instance, the

64 herbicide atrazine can increase susceptibility of amphibian hosts to infection with a trematode

65 parasite by compromising host immunity, leading to variability in infection loads across space

66 (Rohr et al. 2008b). The net effects of environmental conditions on host exposure to pathogens

67 and host susceptibility to infection may explain spatial variability in the prevalence of pathogens

68 (Tompkins et al. 2011, Estrada-Peña et al. 2014). For many wildlife disease systems, the

69 influence of local environmental conditions on exposure and per capita transmission has not been 
adequately evaluated, which is likely leading to challenges in the development of effective strategies for disease surveillance and management.

Understanding how local environmental variability impacts host-pathogen systems can be particularly important when associated with catastrophic host declines. Batrachochytrium dendrobatidis $(\mathrm{Bd})$, for example, is a generalist pathogen that causes the disease chytridiomycosis in amphibians and has been implicated in population declines, extirpation and extinctions of hundreds of amphibian species worldwide (Kilpatrick et al. 2010, Venesky et al. 2014b). Bd is an aquatic pathogen with a motile and infectious zoospore stage, which penetrates and colonizes host tissues containing keratin (Berger et al. 1998, McMahon et al. 2013a, McMahon and Rohr 2015). After colonization, zoospores develop into zoosporangia, which

80 produce and release new zoospores. New zoospores re-infect the same host or are released into

81 the environment (Berger et al. 2005).

Host population persistence and response to Bd are heterogenous (Brannelly et al. 2021); some amphibian host populations are suddenly extirpated, while others persist with endemic Bd transmission (Pilliod et al. 2010, Briggs et al. 2010, Longo and Burrowes 2010). While many studies have investigated sources of variability in Bd infection patterns at large spatial scales

86 (regional to global), which include temperature regime (Liu et al. 2013, James et al. 2015, Cohen

87 et al. 2017), precipitation (Becker and Zamudio 2011, James et al. 2015), altitude (Muths et al.

88 2003, Rohr and Raffel 2010, Lambertini et al. 2021), host community diversity (Venesky et al.

89 2014a, Cohen et al. 2016), and land use practices (Padgett-Flohr and Hopkins 2010, Rumschlag

90 and Rohr 2018, Rumschlag and Boone 2020), less is known about the mechanisms that drive

91 local transmission dynamics. For instance, currently, the relative importance of environmental

92 variation in driving Bd exposure and per capita transmission remains uncertain, which could 
93 have important ramifications for explaining patterns of $\mathrm{Bd}$ infection prevalence across host

94 populations.

95 Neighboring populations of amphibian hosts of the same species can vary tremendously

96 in their Bd infection prevalence (Raffel et al. 2010, Strauss and Smith 2013, Venesky et al.

97 2014a, Chestnut et al. 2014, Rumschlag and Boone 2020). This local-scale variability in patterns

98 of infections could be caused by variation in zoospore mortality, leading to differences in Bd

99 exposure among sites, or by variation in host susceptibility to Bd infection. The main

100 environmental sources of Bd mortality are likely consumption by predators and poor water

101 quality. Protozoa, zooplankton, and filter feeding tadpoles can consume zoospores suspended in

102 the water column, decreasing Bd exposure, and lowering infection rates and loads in amphibian

103 hosts (Buck et al. 2011, Hamilton et al. 2012, Searle et al. 2013, Venesky et al. 2014a, Schmeller

104 et al. 2014). In addition, water quality parameters including pH (Piotrowski et al. 2004, Kärvemo

105 et al. 2018), salinity (Heard et al. 2014, Stockwell et al. 2015, Clulow et al. 2018), temperature

106 (Voyles et al. 2012, Raffel et al. 2015), and the presence of contaminants (McMahon et al.

107 2013b, Rumschlag et al. 2014, Rohr et al. 2017, Rumschlag and Rohr 2018) can influence the

108 survival of zoospores and ability to infect hosts. Simultaneously, local scale variability in

109 infection prevalence could be a result of differences in host susceptibility. In particular,

110 susceptibility of species may vary as a result of differences in water quality (Jani and Briggs

1112018 , Greenspan et al. 2019) or intraspecific population-level differences in susceptibility

112 (Bradley et al. 2015).

113 In addition, dead Bd zoospores and/or the metabolites they produced can induce acquired

114 resistance in amphibian hosts (Ellison et al. 2014, McMahon et al. 2014, Savage et al. 2016). If

115 environmental conditions cause zoospores to die rapidly once they are released from 
116 zoosporangia, hosts could be exposed regularly to dead Bd zoospores. However, if after death Bd

117 decomposes quickly, host exposure to dead Bd zoospores could be minimal. Spatial variability in

118 acquired resistance of hosts through variability in the persistence of dead $\mathrm{Bd}$ and its metabolites

119 could contribute to spatial variability in Bd outbreaks. If composition and densities of zoospore

120 decomposers and scavengers and water quality influence of the persistence of dead Bd or its

121 metabolites in the environment, then variation in these factors at local spatial scales could lead to

122 variation in $\mathrm{Bd}$ disease dynamics.

123 To gain a mechanistic understanding of the potential for variation in local transmission

124 dynamics of $\mathrm{Bd}$, we conducted experiments and fit transmission models to discern how Bd

125 mortality, decomposition, and per capita transmission vary among water sources. We predicted

126 that rates of $\mathrm{Bd}$ zoospore mortality and decomposition would be higher in pond water than

127 artificial spring water (ASW) because ASW lacks any zoospore predators, competitors, and

128 scavengers. High zoospore mortality, in turn, should lead to lower rates of transmission and

129 infection prevalence in frog hosts in pond water compared to ASW. We also hypothesized that

130 there would be significant variation among pond water treatments in rates of $\mathrm{Bd}$ zoospore

131 mortality, decomposition, and infectivity, perhaps because of differences in abiotic conditions or

132 zoospore predators, competitors, and scavengers that can affect environmental persistence of Bd.

MATERIALS AND METHODS

135 Animal Collection and Care

136 We collected multiple clutches of recently hatched Cuban treefrog (Osteopilus

137 septentrionalis) tadpoles at Gosner stage 25 (Gosner 1960) from University of South Florida

138 Botanical Gardens. We maintained the tadpoles in the laboratory for nine days until the start of 
139 the second experiment (described below) at $21 \pm 1^{\circ} \mathrm{C}$ with a $14: 10 \mathrm{hr}$ light:dark photoperiod in

140 tanks containing 90\% artificial spring water (ASW; Cohen et al. 1980) and 10\% rainwater.

141 Tadpoles were fed ad libitum a mixture of fish flakes and spirulina suspended in agar, and water

142 was changed daily. Tadpole survival was checked daily, and no mortality was observed prior to

143 the start of the second experiment.

\section{Bd Inoculate Preparation}

For both experiments, Bd (isolate SRS 810; isolated from Lithobates catesbeianus in

147 USA) was grown on $1 \%$ tryptone agar plates at $23^{\circ} \mathrm{C}$ over $7-10 \mathrm{~d}$. Immediately before use in

148 each experiment, Bd plates were flooded with DI water for 30 min to suspend zoospores. Water

149 containing zoospores was homogenized among plates. The zoospore concentration was

150 determined using a hemocytometer and the solution was diluted to the given target concentration

151 (described below).

\section{Experimental Designs}

To quantify rates of $\mathrm{Bd}$ mortality, decomposition, and per capita transmission in pond

155 water and ASW, we conducted two experiments and used the results of the experiment to inform

156 models estimating Bd mortality, decomposition, and per capita transmission. In the first

157 experiment, we measured concentration of live and dead $\mathrm{Bd}$ zoospores in four water treatments

158 (ASW or pond water from one of three locations: Flatwoods Park, Green Swamp Wilderness

159 Preserve, or Trout Creek Conservation Park) by destructively sampling experimental units across

160 time $(0,6,16,24$, or $48 \mathrm{hrs})$. An experimental unit was $1 \mathrm{ml}$ of zoospores at a concentration of

$161 \quad 125,000$ zoospores/ml plus $1 \mathrm{ml}$ of a given water treatment, and each water treatment-time 
162 combination was replicated 10 times for a total of 200 experimental units. These three sources of

163 pond were selected because previous studies surveying amphibian populations for Bd infections

164 at these three locations have not detected Bd (unpublished data). Pond water was collected from

165 the end of the ponds and was not filtered because we wanted to maintain the natural zoospore

166 predators, competitors, and scavengers. ASW was used to control for the presence of any

167 zoospore predators, competitors, and scavengers.

Survival of zoospores was measured via counts of live and dead zoospores that were

169 stained with Trypan blue (McMahon and Rohr 2014). We added equal parts Trypan and zoospore-water treatment solution before counting live and dead zoospores on a hemocytometer.

171 Cell counting of samples was randomly and evenly assigned to two people. Dissolved oxygen

172 and $\mathrm{pH}$ were taken from the stock sample for each of the water treatments used in the

173 experiment: ASW (9.20 mg/L DO, $6.74 \mathrm{pH})$, Flatwoods (8.50 mg/L DO, $6.66 \mathrm{pH})$, Green

174 Swamp (9.15 mg/L DO, $7.30 \mathrm{pH})$, and Trout Creek (9.40 mg/L DO, $6.38 \mathrm{pH})$. All water

175 treatments were maintained $21^{\circ} \mathrm{C}$ during the experiment.

In a second experiment, we exposed Cuban treefrog tadpoles (Osteopilus septentrionalis)

177 to Bd zoospores in four water treatments (ASW or pond water from one of three locations:

178 Flatwoods Park, Green Swamp Wilderness Preserve, or Trout Creek Conservation Park) at five

179 time lags between the introduction of Bd live zoospores $\left(5 \times 10^{5}\right.$ zoospores $\left./ \mathrm{ml}\right)$ and the

180 introduction of the tadpole $(0,3,6,12$, and $24 \mathrm{hrs})$ in $100 \mathrm{ml}$ of the given water treatment. Each

181 water treatment-time lag combination was replicated ten times with a single tadpole as the

182 experimental unit for a total of 200 tadpoles. Tadpoles were exposed to $\mathrm{Bd}$ in their given water

183 and time lag treatments for $24 \mathrm{hrs}$. Then, every tadpole was transferred to $450 \mathrm{ml} \mathrm{ASW}$ water for

184 two weeks so that they could develop detectable infection, if present. There was no tadpole 
185 mortality. Dissolved oxygen and $\mathrm{pH}$ were taken from the stock sample for each of the water

186 treatments used the second experiment: ASW (7.0 mg/L DO, $7.52 \mathrm{pH})$, Flatwoods $(7.3 \mathrm{mg} / \mathrm{L}$

187 DO, $6.76 \mathrm{pH})$, Green Swamp (7.9 mg/L DO, $7.84 \mathrm{pH})$, and Trout Creek (6.5 mg/L DO, $6.98 \mathrm{pH})$.

188 The experiment was conducted at $21 \pm 1^{\circ} \mathrm{C}$ with a $14: 10 \mathrm{hr}$ light:dark photoperiod. During the

189 experiment, tadpole water was changed once per week and tadpoles were fed ad libitum a

190 mixture of fish flakes and spirulina suspended in agar.

At the end of two weeks, tadpoles were euthanized, and their mouthparts were excised

192 and analyzed for Bd using quantitative PCR (qPCR). To determine the Bd quantity on each

193 tadpole, we followed the qPCR protocol described by Hyatt et al. (2007). Briefly, we used

194 PrepMan Ultra (Applied Biosystems) to extract DNA. To increase extraction efficiency, the

195 mouthpart tissue was placed in a cell disruptor (Disruptor Genie, Scientific Industries) and

196 agitated with $0.035 \pm 0.005 \mathrm{~g}$ of zirconia/silica beads for a total of 2.25 minutes. We used

197 TaqMan Exogenous Internal Positive Control Reagents (Applied Biosystems) to screen for

198 inhibition in all samples. We diluted and re-ran any samples with inhibition.

Mortality, decomposition, and per capita transmission modeling and analysis

We estimated the rates of mortality, decomposition, and per capita transmission of $\mathrm{Bd}$

202 zoospores by fitting a model to the results of the survival and infection experiments. The model

203 used coupled ordinary differential equations to track the concentrations of live zoospores, $Z_{L}$,

204 dead zoospores, $Z_{D}$, susceptible frogs, $S$, and infected frogs, $I$ (Eqs. 1-4, Fig. 1). It assumes a

205 constant background mortality of live zoospores, at per capita rate $m$, a constant decomposition

206 rate of dead zoospores, at per capita rate $d$, and density-dependent transmission via zoospore-

207 frog contact, at transmission rate $\beta$. For tractability, it assumes no host mortality and that 
208 depletion of zoospores via infection (sensu Civitello and Rohr 2014) is negligible relative to

209 zoospore mortality:

210

$$
\frac{d Z_{L}}{d t}=-m Z_{L}
$$

$$
\frac{d Z_{D}}{d t}=m Z_{L}-d Z_{D}
$$

$$
\frac{d S}{d t}=-\beta S Z_{L}
$$

$$
\frac{d I}{d t}=\beta S Z_{L}
$$

Integrating this model yields analytical solutions for the key quantities observed in the

216 depending on the mortality rate, $m$, the initial density of live zoospores, $Z_{L}(0)$, and time, $t$ :

$$
Z_{L}(t)=Z_{L}(0) e^{-m t}
$$

Assuming that there are initially no dead zoospores, $Z_{D}(0)=0$, yields an analytical

219 solution for $Z_{D}(\mathrm{t})$ :

$$
Z_{D}(t)=Z_{L}(0) \frac{m}{d-m}\left(e^{-d t}-e^{-m t}\right)
$$

221 These equations predict the density of live and dead zoospores observable at time $t$. We fit these 222 functions to paired observations of these quantities from the zoospore survival experiment. We 223 assumed independent log-normal errors to obtain likelihoods:

$$
\log \left(Z_{i}(t)_{\text {observed }}+0.1\right) \sim \operatorname{Normal}\left(\log \left(Z_{i}(t)_{\text {Predicted }}+0.1\right), d_{i}\right)
$$

225 where $i=\mathrm{L}, \mathrm{D}$ and $s d_{i}$ is the standard deviation of predictive errors. We added a small quantity,

2260.1 , to each observation and prediction to avoid taking $\log (0)$. the binomial distribution: 


$$
S(t)=S(0) e^{\frac{\beta Z_{L}(0)}{m}\left(e^{-m t}-1\right)}
$$

231 The above equation assumes that hosts and parasites are placed in the environment together at

232 time $t=0$. However, in our infection experiments, we added zoospores to containers at time $t=$

2330 , and then added a single susceptible host after a time lag, $t$, such that $S(t)=1$. We then removed

234 the host individual after an exposure period of length $\tau$ (in our experimental $\tau=1$ day for all

235 treatments). Thus, the tadpole is predicted to be exposed upon its introduction to the

236 concentration of zoospores remaining alive at time $t, Z_{L}(t)$, and the entire trial ends at the total

237 time $t+\tau$. Incorporating these experimental conditions into Eq. 8 yields a specific prediction for

$238 \quad S(t+\tau)$

$$
S(t+\tau)=S(t) e^{\frac{\beta Z_{L}(t)}{m}\left(e^{-m \tau}-1\right)}
$$

240 Substituting $Z_{L}(t)$ from Eq. 5 and simplifying yields:

$$
S(t+\tau)=S(t) e^{\frac{\beta Z_{L}(0) e^{-m t}}{m}}\left(e^{-m \tau}-1\right)
$$

Because the total density of tadpoles never changes, $S(t)$ and $S(t+\tau)$ fully specify prevalence at

243 time $t+\tau, p(t+\tau)$, which we use in the binomial likelihood function:

$$
p(t+\tau)=1-\frac{S(t+\tau)}{S(t)}=1-e^{\frac{\beta Z_{L}(0) e^{-m t}}{m}\left(e^{-m \tau}-1\right)}
$$

245 This quantity specifies the probability of infection in the binomial likelihood, which we calculate

246 for each tadpole, which is diagnosed as infected or uninfected (Rachowicz and Briggs 2007). We

247 combined these likelihood functions (Equations 7 and 11) to generate an overall likelihood for all

248 observations (live zoospores, dead zoospores, and infected hosts) across the two experiments.

With the theoretical and statistical models in place, we estimated parameters (zoospore

250 mortality, zoospore decomposition, and per capita transmission) for a series of 15 transmission

251 models (see Table 1). We tested models that assumed that these three parameters were either 
constant across all water sources, could vary across all four sources, or could vary between ASW

versus the pond waters (as a group). We evaluated the relative performance of this set of 15

models using AICc, Akaike model weights, and importance scores (Burnham and Anderson

255 2002).

RESULTS

rate, $m$, varying among water sources and a common estimate for decomposition, $d$, and per

260 capita transmission, $\beta$, rates fit the data from our zoospore persistence and infectivity

261 experiments best (Table 1). Three models had $\triangle \mathrm{AICc}$ scores less than two, all of which

262 contained varying parameter estimates for $m$ according to the four water sources. None of the

263 models that included varying estimates of $d$ and $\beta$ were better (i.e., more than two AICc lower)

264 than the model that varied $m$ alone. In corroboration, mortality rate fit with four estimates

265 received an importance score of almost one, and per capita transmission rate fit with a single

266 estimate received a greater importance score than per capita transmission rates fit with two or

267 four estimates (Fig. 2A). While the importance score for decomposition rate was highest when it

268 was fit with four estimates (Fig. 2A), this result likely reflected a small difference between

269 decomposition in ASW and pond water from Trout Creek (Fig. 2B). A log-likelihood ratio test

270 supported that the lowest AICc model with the additional complexity of $m$ and $d$ fit with four

271 parameters was not a significant improvement above the model with a single parameter estimate

272 for $d$ and $\beta$ and four parameter estimates according to water treatments for $m\left(\chi^{2}=7.581, d f=3\right.$,

$273 p=0.056)$. So, we have strong evidence that $m$ varied among water sources and weak evidence

274 that $d$ and $\beta$ varied among water sources. 
Model predictions supported lower rates of zoospore mortality in ASW compared to pond water (Fig. 2B). The expected lifespan of a zoospore $( \pm 95 \% \mathrm{CI})$ was $14.4 \pm 2.3 \mathrm{hrs}$ in ASW, $13.3 \pm 2.2 \mathrm{hrs}$ in pond water from Trout Creek, $11.4 \pm 1.6 \mathrm{hrs}$ in pond water from Flatwoods, and $9.4 \pm 1.1$ hrs in pond water from Green Swamp. There were no obvious patterns between mortality rate of zoospores and $\mathrm{DO}$ and $\mathrm{pH}$ measurements across water treatments. These

280 differences in mortality rates led to differences in the concentrations of live and dead zoospores

281 across time (Fig. 3). The model predicted that the concentration of live zoospores in ASW was

282 consistently greater across time than the concentration of live zoospores in water from any of the 283 three ponds (Fig. 3A).

While the zoospore mortality rates varied across water treatments, the best model

285 suggested that decomposition rates of zoospores did not. Overall, the expected persistence time

286 of a zoospore $( \pm 95 \% \mathrm{CI})$ was $21.6 \pm 5.2 \mathrm{hrs}$. Persistence time in the model was defined as the

287 average time from the death of a zoospore to complete decomposition. The concentration of dead

288 Bd zoospores over time was non-monotonic, with an initial increase as zoospores died and then a

289 decrease after $16 \mathrm{hrs}$, caused by decomposition of dead zoospores (Fig. 3B). While the rate of

290 decomposition of zoospores did not vary across water treatments, the mean concentration of dead

291 zoospores experimentally measured was substantially greater in ASW at the $48 \mathrm{hr}$ experimental

292 time point (Fig. 3B), suggesting lower rates of decomposition in accordance with predictions.

$294{ }^{6} \pm 2.6 \times 10^{-6}(95 \% \mathrm{CI})$, and that this rate did not vary across water treatments. Predicted infection

295 prevalence, which depends on both per capita rate of transmission, $\beta$, and zoospore mortality

296 rate, $m$, decreased across time as zoospores died (Fig. 4A). Differences in zoospore mortality

297 rate, but not per capita transmission rate, led to differences in infection prevalence across time; 
298 infection prevalence was greater in ASW compared to pond water sources across time (Fig. 4A).

299 The transmission model also predicted a positive association between host infection prevalence

300 and concentration of live zoospores with the highest rates of infection prevalence and the greatest

301 concentration of live zoospores occurring in ASW (Fig. 4B).

\section{DISCUSSION}

To gain a mechanistic understanding of the potential for local variation in transmission

305 dynamics of $\mathrm{Bd}$, we conducted $\mathrm{Bd}$ survival and infection experiments and then fit models to

306 evaluate how Bd mortality, decomposition, and per-capita transmission rates varied among water

307 sources. Results showed that infection prevalence differed among water sources, which was

308 driven indirectly by differences in mortality rates of Bd zoospores and not by differences in per-

309 capita transmission rates. More specifically, zoospore mortality rates varied among pond water

310 sources and were lower in ASW compared to pond water. These differences among pond water

311 sources suggest that local variation in $\mathrm{Bd}$ infection dynamics could be a function of differences

312 in Bd exposure. In contrast to the differences in mortality rates of live zoospores among water

313 sources, we found that rates of decomposition of dead zoospores did not vary. These results

314 could suggest that exposure of amphibian hosts to dead $\mathrm{Bd}$ and its metabolites, which have been

315 shown to induce acquired resistance (Ellison et al. 2014, McMahon et al. 2014, Savage et al.

316 2016), might not commonly vary among nearby sites.

317 Consistent with our predictions, we found that Bd mortality rates varied among pond

318 water sources and that the lowest rates of mortality occurred in ASW compared to pond water.

319 We hypothesized that differences in the predators and/or competitors of live $\mathrm{Bd}$ zoospores drove

320 the differences between ASW and pond water. Protozoa and zooplankton consume live 
321 zoospores in the water column, decreasing live zoospore persistence and thus infection rates and

322 loads in amphibian hosts (Buck et al. 2011, Hamilton et al. 2012, Searle et al. 2013, Schmeller et

323 al. 2014). Among ponds, mortality rates differed (e.g. Trout Creek versus Green Swamp, Fig.

324 2B), which conceivably could have been driven by differences in the densities and/or

325 compositions of predators and consumers. While trends in mortality rates across water treatments

326 did not align with $\mathrm{pH}$ and dissolved oxygen measurements, given the relatively low sample size,

327 the direct effects of water quality on Bd mortality cannot be ruled out as an alternative

328 hypothesis.

In addition, the lower rates of mortality in ASW compared to pond water sources suggest

330 lab studies of $\mathrm{Bd}$ infection are likely to consistently overestimate transmission rates relative to

331 field or mesocosm studies. More often than not, lab studies use a medium, like ASW, distilled

332 water, or sterilized pond water, to expose hosts to $\mathrm{Bd}$, and these media lack natural $\mathrm{Bd}$ predators

333 and competitors, likely leading to low Bd mortality and higher infection rates in hosts compared

334 to field or mesocosm studies, which include Bd predators and competitors (Sauer et al. 2020).

335 Experimental designs for studies that seek to predict Bd transmission should consider including a

336 water source that contains natural and living communities of zooplankton, protozoa, and other

337 microbes, given the influence of pond water sources on Bd zoospore mortality rates found in the

338 present study.

Differences in Bd mortality across water treatments indirectly resulted in differences in

340 infection prevalence with the greatest rates of infection prevalence in ASW compared to all pond

341 water sources. Across treatments, infection prevalence was positively predicted by the

342 concentration of live Bd zoospores. We suggest that consumption of live $\mathrm{Bd}$ zoospores by

343 protozoa and zooplankton in pond water could have led to decreases in rates of Bd prevalence in 
344 pond water treatments; however, future experiments should test this explicitly. We found no

345 evidence that differences in per capita Bd transmission rates across water treatments directly

346 influenced infection prevalence. Susceptibility of the focal amphibian species and infectivity of

347 Bd zoospores possibly did not vary with exposure to different water sources.

348 Finally, we found that as a result of similarities in the decomposition rates of Bd

349 zoospores across water sources, concentrations of dead Bd through time did not vary among

350 water sources. These results could suggest that exposure of amphibian hosts to dead Bd and its

351 metabolites, which can induce acquired resistance in amphibian hosts (Ellison et al. 2014,

352 McMahon et al. 2014, Savage et al. 2016), might not commonly vary among local sites,

353 assuming a similar degree of similarity in Bd scavenger and decomposer communities and water

354 quality parameters compared to those in the current study. While we did not directly examine

355 rates of decomposition of Bd metabolites, we might assume similarities in the rates of

356 decomposition of Bd zoospores and metabolites, though future studies should be completed to

357 evaluate this assumption. We know of no other study that has directly estimated decomposition

358 rates of any life stage of $\mathrm{Bd}$, which could be an important consideration in understanding spatial

359 and temporal variability in acquired resistance in natural host populations. Scientists are

360 currently considering how to aid amphibian hosts in developing acquired resistance against Bd as

361 a management strategy to limit the spread of chytridiomycosis. These ongoing efforts could be

362 informed by a better understanding the decomposition of $\mathrm{Bd}$ and its metabolites under natural

363 conditions.

364 While considerable efforts have been undertaken by researchers over the last twenty

365 years to uncover the environmental drivers of the spread of Bd (Kilpatrick et al. 2010, James et

366 al. 2015, Fisher and Garner 2020), additional insights into variability in Bd zoospore mortality, 
367 decomposition, and per capita transmission could aid in understanding outbreak heterogeneity

368 among host populations. Our results show that differences in infection prevalence can be

369 mechanistically driven by differences in Bd zoospore mortality but not per capita transmission

370 rates. These results indicate that differences in mortality of Bd zoospores among neighboring

371 sites have the potential to drive local scale patterns of disease dynamics. Further, we show that

372 Bd decomposition is similar across water sources from neighboring sites; these results suggests

373 that exposure of hosts to dead Bd and/or its metabolites, which may lead to acquired resistance,

374 could be similar at small spatial scales. Increased attention towards the effects of local scale

375 variability in pathogen mortality, decomposition, and per capita transmission may increase the

376 efficacy of efforts to surveil and manage wildlife infectious diseases (Cunningham et al. 2017,

377 Barnett and Civitello 2020).

379 ACKNOWLEDGEMENTS. - This research was supported by grants from the National Science

380 Foundation (J.R.R.: DEB-2017785, DEB-1518681, IOS-1754868, T.A.M.: IOS-1754862,

381 D.J.C: IOS-1755002), National Institutes of Health (J.R.R.: R01TW010286; T.A.M.:

382 1R01GM135935-01, subaward: KK2022), US Department of Agriculture (2021-38420-34065)

383 to JRR, and the John Wesley Powell Center for Analysis and Synthesis, funded by the U.S.

384 Geological Survey, as a part of the Analyses of Contaminant Effects in Freshwater Systems

385 Working Group to J.R.R. and S.L.R. We would like to acknowledge Joyce Longcore for

386 providing the $\mathrm{Bd}$ isolate. 
REFERENCES

Barnett, K. M., and D. J. Civitello. 2020. Ecological and Evolutionary Challenges for Wildlife Vaccination. Trends in Parasitology 36:970-978.

Becker, C. G., and K. R. Zamudio. 2011. Tropical amphibian populations experience higher disease risk in natural habitats. Proceedings of the National Academy of Sciences 108:9893-9898.

Berger, L., A. D. Hyatt, R. Speare, and J. E. Longcore. 2005. Life cycle stages of the amphibian chytrid Batrachochytrium dendrobatidis. Diseases of Aquatic Organisms 68:51-63.

Berger, L., R. Speare, P. Daszak, D. E. Green, A. A. Cunningham, C. L. Goggin, R. Slocombe, M. A. Ragan, A. D. Hyatt, K. R. McDonald, H. B. Hines, K. R. Lips, G. Marantelli, and H. Parkes. 1998. Chytridiomycosis causes amphibian mortality associated with population declines in the rain forests of Australia and Central America. Proceedings of the National Academy of Sciences 95:9031-9036.

Bradley, P. W., S. S. Gervasi, J. Hua, R. D. Cothran, R. A. Relyea, D. H. Olson, and A. R. Blaustein. 2015. Differences in sensitivity to the fungal pathogen Batrachochytrium dendrobatidis among amphibian populations. Conservation Biology 29:1347-1356.

Brannelly, L. A., H. I. McCallum, L. F. Grogan, C. J. Briggs, M. P. Ribas, M. Hollanders, T. Sasso, M. F. López, D. A. Newell, and A. M. Kilpatrick. 2021. Mechanisms underlying host persistence following amphibian disease emergence determine appropriate management strategies. Ecology Letters 24:130-148.

Briggs, C. J., R. A. Knapp, and V. T. Vredenburg. 2010. Enzootic and epizootic dynamics of the chytrid fungal pathogen of amphibians. Proceedings of the National Academy of Sciences 107:9695-9700.

Buck, J. C., L. Truong, and A. R. Blaustein. 2011. Predation by zooplankton on Batrachochytrium dendrobatidis: biological control of the deadly amphibian chytrid fungus? Biodiversity and Conservation 20:3549-3553.

Burnham, K. P., and D. R. Anderson. 2002. Model selection and multimodel inference: a practical information-theoretic approach. 2nd ed. Springer, New York.

Chestnut, T., C. Anderson, R. Popa, A. R. Blaustein, M. Voytek, D. H. Olson, and J. Kirshtein. 2014. Heterogeneous Occupancy and Density Estimates of the Pathogenic Fungus Batrachochytrium dendrobatidis in Waters of North America. PLOS ONE 9:e106790.

Civitello, D. J., S. Pearsall, M. A. Duffy, and S. R. Hall. 2013. Parasite consumption and host interference can inhibit disease spread in dense populations. Ecology Letters 16:626-634.

Civitello, D. J., and J. R. Rohr. 2014. Disentangling the effects of exposure and susceptibility on transmission of the zoonotic parasite Schistosoma mansoni. Journal of Animal Ecology 83:1379-1386.

Clulow, S., J. Gould, H. James, M. Stockwell, J. Clulow, and M. Mahony. 2018. Elevated salinity blocks pathogen transmission and improves host survival from the global amphibian chytrid pandemic: Implications for translocations. Journal of Applied Ecology 55:830-840.

Cohen, J. M., D. J. Civitello, A. J. Brace, E. M. Feichtinger, C. N. Ortega, J. C. Richardson, E. L. Sauer, X. Liu, and J. R. Rohr. 2016. Spatial scale modulates the strength of ecological processes driving disease distributions. Proceedings of the National Academy of Sciences 113:E3359-E3364. 
Cohen, J. M., M. D. Venesky, E. L. Sauer, D. J. Civitello, T. A. McMahon, E. A. Roznik, and J. R. Rohr. 2017. The thermal mismatch hypothesis explains host susceptibility to an emerging infectious disease. Ecology Letters 20:184-193.

Cohen, L. M., H. Neimark, and L. K. Eveland. 1980. Schistosoma mansoni: Response of Cercariae to a Thermal Gradient. The Journal of Parasitology 66:362-364.

Cunningham, A. A., P. Daszak, and J. L. N. Wood. 2017. One Health, emerging infectious diseases and wildlife: two decades of progress? Philosophical Transactions of the Royal Society B: Biological Sciences 372:20160167.

Ellison, A. R., A. E. Savage, G. V. DiRenzo, P. Langhammer, K. R. Lips, and K. R. Zamudio. 2014. Fighting a losing battle: vigorous immune response countered by pathogen suppression of host defenses in the chytridiomycosis-susceptible frog Atelopus zeteki. G3 (Bethesda, Md.) 4:1275-1289.

Estrada-Peña, A., R. S. Ostfeld, A. T. Peterson, R. Poulin, and J. de la Fuente. 2014. Effects of environmental change on zoonotic disease risk: an ecological primer. Trends in Parasitology 30:205-214.

Favier, C., D. Schmit, C. D. M. Müller-Graf, B. Cazelles, N. Degallier, B. Mondet, and M. A. Dubois. 2005. Influence of spatial heterogeneity on an emerging infectious disease: the case of dengue epidemics. Proceedings of the Royal Society B: Biological Sciences 272:1171-1177.

Fisher, M. C., and T. W. J. Garner. 2020. Chytrid fungi and global amphibian declines. Nature Reviews Microbiology 18:332-343.

Gandon, S., T. Day, C. J. E. Metcalf, and B. T. Grenfell. 2016. Forecasting Epidemiological and Evolutionary Dynamics of Infectious Diseases. Trends in Ecology \& Evolution 31:776788.

Gosner, K. L. 1960. A Simplified Table for Staging Anuran Embryos and Larvae with Notes on Identification. Herpetologica 16:183-190.

Greenspan, S. E., M. L. Lyra, G. H. Migliorini, M. F. Kersch-Becker, M. C. Bletz, C. S. Lisboa, M. R. Pontes, L. P. Ribeiro, W. J. Neely, F. Rezende, G. Q. Romero, D. C. Woodhams, C. F. B. Haddad, L. F. Toledo, and C. G. Becker. 2019. Arthropod-bacteria interactions influence assembly of aquatic host microbiome and pathogen defense. Proceedings of the Royal Society B: Biological Sciences 286:20190924.

Hamilton, P. T., J. M. L. Richardson, and B. R. Anholt. 2012. Daphnia in tadpole mesocosms: trophic links and interactions with Batrachochytrium dendrobatidis. Freshwater Biology 57:676-683.

Heard, G. W., M. P. Scroggie, N. Clemann, and D. S. L. Ramsey. 2014. Wetland characteristics influence disease risk for a threatened amphibian. Ecological Applications 24:650-662.

Hyatt, A. D., D. G. Boyle, V. Olsen, D. B. Boyle, L. Berger, D. Obendorf, A. Dalton, K. Kriger, M. Hero, H. Hines, R. Phillott, R. Campbell, G. Marantelli, F. Gleason, and A. Colling. 2007. Diagnostic assays and sampling protocols for the detection of Batrachochytrium dendrobatidis. Diseases of Aquatic Organisms 73:175-192.

James, T. Y., L. F. Toledo, D. Rödder, D. da S. Leite, A. M. Belasen, C. M. Betancourt-Román, T. S. Jenkinson, C. Soto-Azat, C. Lambertini, A. V. Longo, J. Ruggeri, J. P. Collins, P. A. Burrowes, K. R. Lips, K. R. Zamudio, and J. E. Longcore. 2015. Disentangling host, pathogen, and environmental determinants of a recently emerged wildlife disease: lessons from the first 15 years of amphibian chytridiomycosis research. Ecology and Evolution 5:4079-4097. 
Jani, A. J., and C. J. Briggs. 2018. Host and Aquatic Environment Shape the Amphibian Skin Microbiome but Effects on Downstream Resistance to the Pathogen Batrachochytrium dendrobatidis Are Variable. Frontiers in Microbiology 9.

Kärvemo, S., S. Meurling, D. Berger, J. Höglund, and A. Laurila. 2018. Effects of host species and environmental factors on the prevalence of Batrachochytrium dendrobatidis in northern Europe. PLOS ONE 13:e0199852.

Kilpatrick, A. M., C. J. Briggs, and P. Daszak. 2010. The ecology and impact of chytridiomycosis: an emerging disease of amphibians. Trends in Ecology \& Evolution 25:109-118.

Koprivnikar, J., D. Lim, C. Fu, and S. H. M. Brack. 2010. Effects of temperature, salinity, and $\mathrm{pH}$ on the survival and activity of marine cercariae. Parasitology Research 106:11671177.

Lambertini, C., C. G. Becker, A. M. Belasen, A. Valencia-Aguilar, C. H. L. Nunes-de-Almeida, C. M. Betancourt-Román, D. Rodriguez, D. da Silva Leite, I. S. Oliveira, J. L. Gasparini, J. Ruggeri, T. Mott, T. S. Jenkinson, T. Y. James, K. R. Zamudio, and L. F. Toledo. 2021. Biotic and abiotic determinants of Batrachochytrium dendrobatidis infections in amphibians of the Brazilian Atlantic Forest. Fungal Ecology 49:100995.

Lei, F., and R. Poulin. 2011. Effects of salinity on multiplication and transmission of an intertidal trematode parasite. Marine Biology 158:995-1003.

Liu, X., J. R. Rohr, and Y. Li. 2013. Climate, vegetation, introduced hosts and trade shape a global wildlife pandemic. Proceedings of the Royal Society B: Biological Sciences 280:20122506.

Longo, A. V., and P. A. Burrowes. 2010. Persistence with Chytridiomycosis does not assure survival of direct-developing frogs. EcoHealth 7:185-195.

McMahon, T. A., L. A. Brannelly, M. W. H. Chatfield, P. T. J. Johnson, M. B. Joseph, V. J. McKenzie, C. L. Richards-Zawacki, M. D. Venesky, and J. R. Rohr. 2013a. Chytrid fungus Batrachochytrium dendrobatidis has nonamphibian hosts and releases chemicals that cause pathology in the absence of infection. Proceedings of the National Academy of Sciences 110:210-215.

McMahon, T. A., and J. R. Rohr. 2014. Trypan blue dye is an effective and inexpensive way to determine the viability of Batrachochytrium dendrobatidis zoospores. EcoHealth 11:164167.

McMahon, T. A., and J. R. Rohr. 2015. Transition of chytrid fungus infection from mouthparts to hind limbs during amphibian metamorphosis. EcoHealth 12:188-193.

McMahon, T. A., J. M. Romansic, and J. R. Rohr. 2013b. Nonmonotonic and Monotonic Effects of Pesticides on the Pathogenic Fungus Batrachochytrium dendrobatidis in Culture and on Tadpoles. Environmental Science \& Technology 47:7958-7964.

McMahon, T. A., B. F. Sears, M. D. Venesky, S. M. Bessler, J. M. Brown, K. Deutsch, N. T. Halstead, G. Lentz, N. Tenouri, S. Young, D. J. Civitello, N. Ortega, J. S. Fites, L. K. Reinert, L. A. Rollins-Smith, T. R. Raffel, and J. R. Rohr. 2014. Amphibians acquire resistance to live and dead fungus overcoming fungal immunosuppression. Nature 511:224-227.

Munster, V. J., C. Baas, P. Lexmond, J. Waldenström, A. Wallensten, T. Fransson, G. F. Rimmelzwaan, W. E. P. Beyer, M. Schutten, B. Olsen, A. D. M. E. Osterhaus, and R. A. M. Fouchier. 2007. Spatial, Temporal, and Species Variation in Prevalence of Influenza A Viruses in Wild Migratory Birds. PLOS Pathogens 3:e61. 
Muths, E., P. Stephen Corn, A. P. Pessier, and D. Earl Green. 2003. Evidence for disease-related amphibian decline in Colorado. Biological Conservation 110:357-365.

Ostfeld, R. S., G. E. Glass, and F. Keesing. 2005. Spatial epidemiology: an emerging (or reemerging) discipline. Trends in Ecology \& Evolution 20:328-336.

Padgett-Flohr, G. E., and R. L. Hopkins. 2010. Landscape epidemiology of Batrachochytrium dendrobatidis in central California. Ecography 33:688-697.

Pilliod, D. S., E. Muths, R. D. Scherer, P. E. Bartelt, P. S. Corn, B. R. Hossack, B. A. Lambert, R. Mccaffery, and C. Gaughan. 2010. Effects of Amphibian Chytrid Fungus on Individual Survival Probability in Wild Boreal Toads: Toad Survival of Chytridiomycosis. Conservation Biology 24:1259-1267.

Piotrowski, J. S., S. L. Annis, and J. E. Longcore. 2004. Physiology of Batrachochytrium dendrobatidis, a Chytrid Pathogen of Amphibians. Mycologia 96:9-15.

Plowright, R. K., S. H. Sokolow, M. E. Gorman, P. Daszak, and J. E. Foley. 2008. Causal inference in disease ecology: investigating ecological drivers of disease emergence. Frontiers in Ecology and the Environment 6:420-429.

Rachowicz, L. J., and C. J. Briggs. 2007. Quantifying the disease transmission function: effects of density on Batrachochytrium dendrobatidis transmission in the mountain yellowlegged frog Rana muscosa. Journal of Animal Ecology 76:711-721.

Raffel, T. R., N. T. Halstead, T. A. McMahon, A. K. Davis, and J. R. Rohr. 2015. Temperature variability and moisture synergistically interact to exacerbate an epizootic disease. Proceedings of the Royal Society B: Biological Sciences 282:20142039.

Raffel, T. R., P. J. Michel, E. W. Sites, and J. R. Rohr. 2010. What Drives Chytrid Infections in Newt Populations? Associations with Substrate, Temperature, and Shade. EcoHealth 7:526-536.

Rohr, J. R., J. Brown, W. A. Battaglin, T. A. McMahon, and R. A. Relyea. 2017. A pesticide paradox: fungicides indirectly increase fungal infections. Ecological Applications 27:2290-2302.

Rohr, J. R., and T. R. Raffel. 2010. Linking global climate and temperature variability to widespread amphibian declines putatively caused by disease. Proceedings of the National Academy of Sciences 107:8269-8274.

Rohr, J. R., T. R. Raffel, S. K. Sessions, and P. J. Hudson. 2008a. Understanding the net effects of pesticides on amphibian trematode infections. Ecological Applications 18:1743-1753.

Rohr, J. R., A. M. Schotthoefer, T. R. Raffel, H. J. Carrick, N. Halstead, J. T. Hoverman, C. M. Johnson, L. B. Johnson, C. Lieske, M. D. Piwoni, P. K. Schoff, and V. R. Beasley. 2008b. Agrochemicals increase trematode infections in a declining amphibian species. Nature 455:1235-1239.

Rumschlag, S. L., and M. D. Boone. 2020. Amphibian Infection Risk Changes with Host Life Stage and across a Landscape Gradient. Journal of Herpetology 54:347-354.

Rumschlag, S. L., M. D. Boone, and G. Fellers. 2014. The effects of the amphibian chytrid fungus, insecticide exposure, and temperature on larval anuran development and survival. Environmental Toxicology and Chemistry 33:2545-2550.

Rumschlag, S. L., N. T. Halstead, J. T. Hoverman, T. R. Raffel, H. J. Carrick, P. J. Hudson, and J. R. Rohr. 2019. Effects of pesticides on exposure and susceptibility to parasites can be generalised to pesticide class and type in aquatic communities. Ecology Letters 22:962972. 
Rumschlag, S. L., and J. R. Rohr. 2018. The influence of pesticide use on amphibian chytrid fungal infections varies with host life stage across broad spatial scales. Global Ecology and Biogeography 27:1277-1287.

Sauer, E. L., J. M. Cohen, M. J. Lajeunesse, T. A. McMahon, D. J. Civitello, S. A. Knutie, K. Nguyen, E. A. Roznik, B. F. Sears, S. Bessler, B. K. Delius, N. Halstead, N. Ortega, M. D. Venesky, S. Young, and J. R. Rohr. 2020. A meta-analysis reveals temperature, dose, life stage, and taxonomy influence host susceptibility to a fungal parasite. Ecology 101:e02979.

Savage, A. E., K. A. Terrell, B. Gratwicke, N. M. Mattheus, L. Augustine, and R. C. Fleischer. 2016. Reduced immune function predicts disease susceptibility in frogs infected with a deadly fungal pathogen. Conservation Physiology 4:cow011.

Schmeller, D. S., M. Blooi, A. Martel, T. W. J. Garner, M. C. Fisher, F. Azemar, F. C. Clare, C. Leclerc, L. Jäger, M. Guevara-Nieto, A. Loyau, and F. Pasmans. 2014. Microscopic Aquatic Predators Strongly Affect Infection Dynamics of a Globally Emerged Pathogen. Current Biology 24:176-180.

Searle, C. L., J. R. Mendelson, L. E. Green, and M. A. Duffy. 2013. Daphnia predation on the amphibian chytrid fungus and its impacts on disease risk in tadpoles. Ecology and Evolution 3:4129-4138.

Stockwell, M. P., J. Clulow, and M. J. Mahony. 2015. Evidence of a salt refuge: chytrid infection loads are suppressed in hosts exposed to salt. Oecologia 177:901-910.

Strauss, A., and K. G. Smith. 2013. Why Does Amphibian Chytrid (Batrachochytrium dendrobatidis) Not Occur Everywhere? An Exploratory Study in Missouri Ponds. PLOS ONE 8:e76035.

Tompkins, D. M., A. M. Dunn, M. J. Smith, and S. Telfer. 2011. Wildlife diseases: from individuals to ecosystems. Journal of Animal Ecology 80:19-38.

Venesky, M. D., X. Liu, E. L. Sauer, and J. R. Rohr. 2014a. Linking manipulative experiments to field data to test the dilution effect. Journal of Animal Ecology 83:557-565.

Venesky, M. D., T. R. Raffel, T. A. McMahon, and J. R. Rohr. 2014b. Confronting inconsistencies in the amphibian-chytridiomycosis system: implications for disease management: Managing chytridiomycosis and amphibians. Biological Reviews 89:477483.

Voyles, J., L. R. Johnson, C. J. Briggs, S. D. Cashins, R. A. Alford, L. Berger, L. F. Skerratt, R. Speare, and E. B. Rosenblum. 2012. Temperature alters reproductive life history patterns in Batrachochytrium dendrobatidis, a lethal pathogen associated with the global loss of amphibians. Ecology and Evolution 2:2241-2249.

Wood, M. J., C. L. Cosgrove, T. A. Wilkin, S. C. L. Knowles, K. P. Day, and B. C. Sheldon. 2007. Within-population variation in prevalence and lineage distribution of avian malaria in blue tits, Cyanistes caeruleus. Molecular Ecology 16:3263-3273. 
608 Figure 1. Conceptual diagram of the model which uses coupled ordinary differential equations to

609 track the concentrations of live zoospores, $Z_{L}$, dead zoospores, $Z_{D}$, susceptible frogs, $S$, and

610 infected frogs, $I$. The model assumes a constant background mortality of live zoospores, at per

611 capita rate $m$, a constant decomposition rate of dead zoospores, at per capita rate $d$, and density-

612 dependent transmission via zoospore-frog contact, at transmission rate $\beta$.

613

614 Figure 2. A) Importance scores of mortality, $m$, decomposition, $d$, and per capita transmission,

$615 \beta$, parameters fit with single estimates, two estimates (ASW or pond water), or four estimates

616 (ASW or pond water from Flatwoods Park, Green Swamp Wilderness Preserve, or Trout Creek

617 Conservation Park). Importance scores were calculated as the sum of the Akaike weights of

618 models including the given parameter (Table 1). Importance scores were greatest for mortality

619 and decomposition rates fit with four estimates according to water sources, while importance

620 score was greatest for per capita transmission fit with a single estimate. B) Parameter estimates

621 for mortality, $m$, decomposition, $d$, and per capita transmission, $\beta$, from a model including four

622 separate estimates according to water source for each parameter. Error estimates are $95 \%$

623 confidence intervals. Mortality varied significantly among water treatments with the lowest rates

624 of mortality in ASW. Decomposition did not show as great of differences among water

625 treatments compared to mortality, though the largest differences in decomposition were between

626 ASW and pond water from Trout Creek. Per capita transmission did not vary among the four

627 water sources.

629 Figure 3. Best-fit predictions of concentrations of A) live and B) dead zoospores across time

630 from the transmission model. A) The concentration of live zoospores decreased across time, 
631 driven by differences in mortality rates across the four water treatments (ASW or pond water

632 from Flatwoods Park, Green Swamp Wilderness Preserve, or Trout Creek Conservation Park).

633 The highest concentrations of live zoospores were in ASW, as predicted. Measured means and

634 standard errors of concentrations of live zoospores across time are provided. B) The

635 concentration of dead Bd zoospores over time was non-monotonic, with an initial increase as

636 zoospores died, driven by differences in mortality rates across water sources, and then a decrease

637 after $16 \mathrm{hrs}$, caused by decomposition or scavenging of dead zoospores. The model predicted the

638 concentration of dead zoospores did not differ across water treatments; although at 48 hrs, the

639 measured concentration of dead zoospores was significantly greater in ASW, suggesting lower

640 rates of decomposition or scavenging in accordance with predictions. Measured means and

641 standard errors of concentrations of dead zoospores across time are provided.

643 Figure 4. A) Best-fit predictions for prevalence of Bd infections across time from the

644 transmission model. Infection prevalence, which was informed by both zoospore mortality and

645 transmission, decreased across time as zoospores died. Differences across water sources in

646 zoospore mortality, but not per capita transmission, led to differences in infection prevalence

647 with the highest infection prevalence across time in ASW. Measured means and binomial

648 standard errors of infection prevalence are provided. B) Best-fit predictions for prevalence of $\mathrm{Bd}$

649 infections against concentration of live $\mathrm{Bd}$ zoospores. The transmission model predicts a positive

650 association between host infection prevalence and concentration of live zoospores with the

651 highest rates of infection prevalence and the greatest concentration of live zoospores occurring in

652 ASW. 
654 Table 1. Results of the model competition analysis for 15 models fit to the Bd zoospore

655 mortality, decomposition, and infection data. Models differed based on whether mortality $(m)$,

656 decomposition $(d)$, and transmission $(\beta)$ parameters were fit with a single, common estimate

657 among the four water sources (Parameters with Single Estimates), with two estimates that

658 corresponded to whether the water source was ASW or pond water (Parameters with Two

659 Estimates), or with four estimates that corresponded to each water source (ASW or pond water

660 from Flatwoods Park, Green Swamp Wilderness Preserve, or Trout Creek Conservation Park).

661 Model competition results suggest that mortality, $m$, varied among water sources, but the other

662 two parameters do not.

\begin{tabular}{ccccccc}
\hline $\begin{array}{c}\text { Parameters } \\
\text { with } \\
\begin{array}{c}\text { Single } \\
\text { Estimates }\end{array}\end{array}$ & $\begin{array}{c}\text { Parameters } \\
\text { with Two } \\
\text { Estimates }\end{array}$ & $\begin{array}{c}\text { Parameters } \\
\text { with Four } \\
\text { Estimates }\end{array}$ & df & AICc & $\Delta$ AICc & weight \\
\hline$\beta$ & - & $m, d$ & 12 & 1377.9 & 0 & 0.40 \\
- & - & $m, d, \beta$ & 15 & 1379 & 1.1 & 0.24 \\
$d, \beta$ & - & $m$ & 9 & 1379.2 & 1.2 & 0.22 \\
$d$ & - & $m, \beta$ & 12 & 1380.2 & 2.2 & 0.13 \\
$\beta$ & $m, d$ & - & 8 & 1385 & 7.1 & 0.01 \\
$d, \beta$ & $m$ & - & 7 & 1389.1 & 11.2 & 0.002 \\
$m, \beta$ & $m, d, \beta$ & - & 9 & 1389.7 & 11.8 & 0.001 \\
$m$ & $d$ & - & 7 & 1391.8 & 13.9 & $<0.001$ \\
$d$ & $m, \beta$ & - & 8 & 1392 & 14.1 & $<0.001$ \\
$m, \beta$ & $-\beta$ & - & 8 & 1393.9 & 15.9 & $<0.001$ \\
$m, d, \beta$ & - & $d$ & 9 & 1395 & 17.1 & $<0.001$ \\
$m, d$ & $\beta$ & - & 6 & 1396.5 & 18.6 & $<0.001$ \\
$m$ & - & - & 7 & 1396.7 & 18.8 & $<0.001$ \\
$m, d$ & - & $\beta$ & 12 & 1397.2 & 19.3 & $<0.001$ \\
& & & 9 & 1398.7 & 20.8 & $<0.001$ \\
\hline
\end{tabular}

663 
bioRxiv preprint doi: https://doi org/10.1101/2021.03.17.435818; this version posted March 19, 2021. The copyright holder for this preprint (which was not certified by peer review) is the author/funder, who has granted bioRxiv a license to display the preprint in perpetuity. It is made available under aCC-BY-NC-ND 4.0 International license.

\section{Figure 1.}

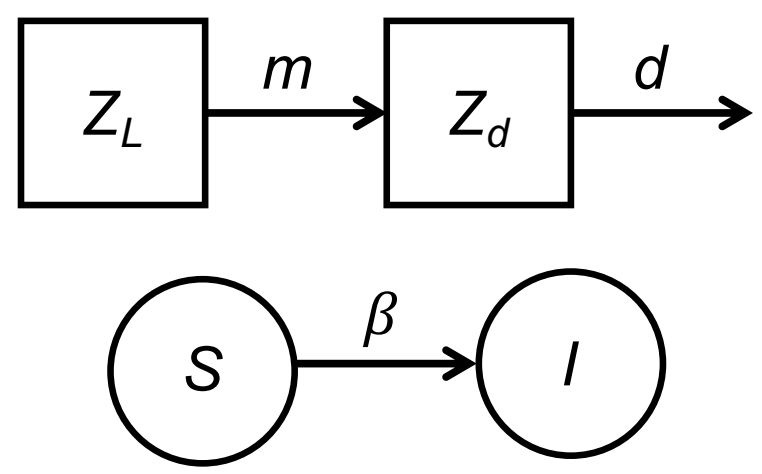


bioRxiv preprint doi: https://doi.org/10.1101/2021.03.17.435818; this version posted March 19, 2021. The copyright holder for this preprint (which was not certified by peer review) is the author/funder, who has granted bioRxiv a license to display the preprint in perpetuity. It is made available under aCC-BY-NC-ND 4.0 International license.

\section{Figure 2.}
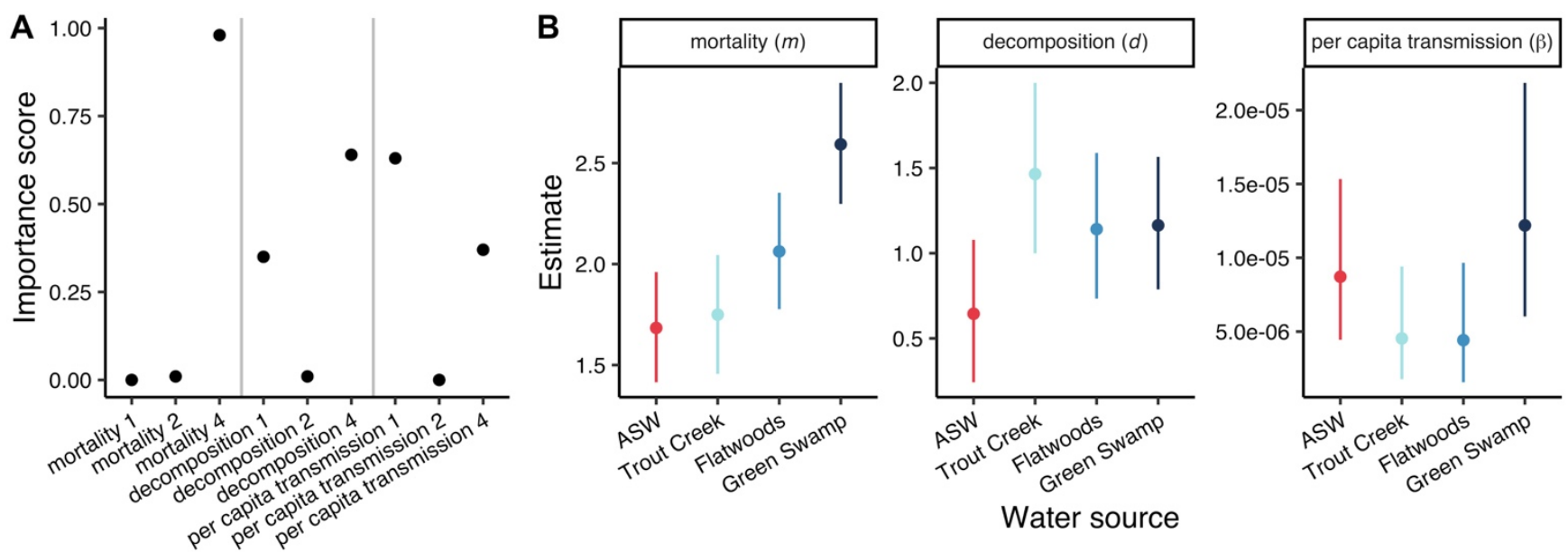

Parameters with 1,2 , or 4 estimates 
667 Figure 3.
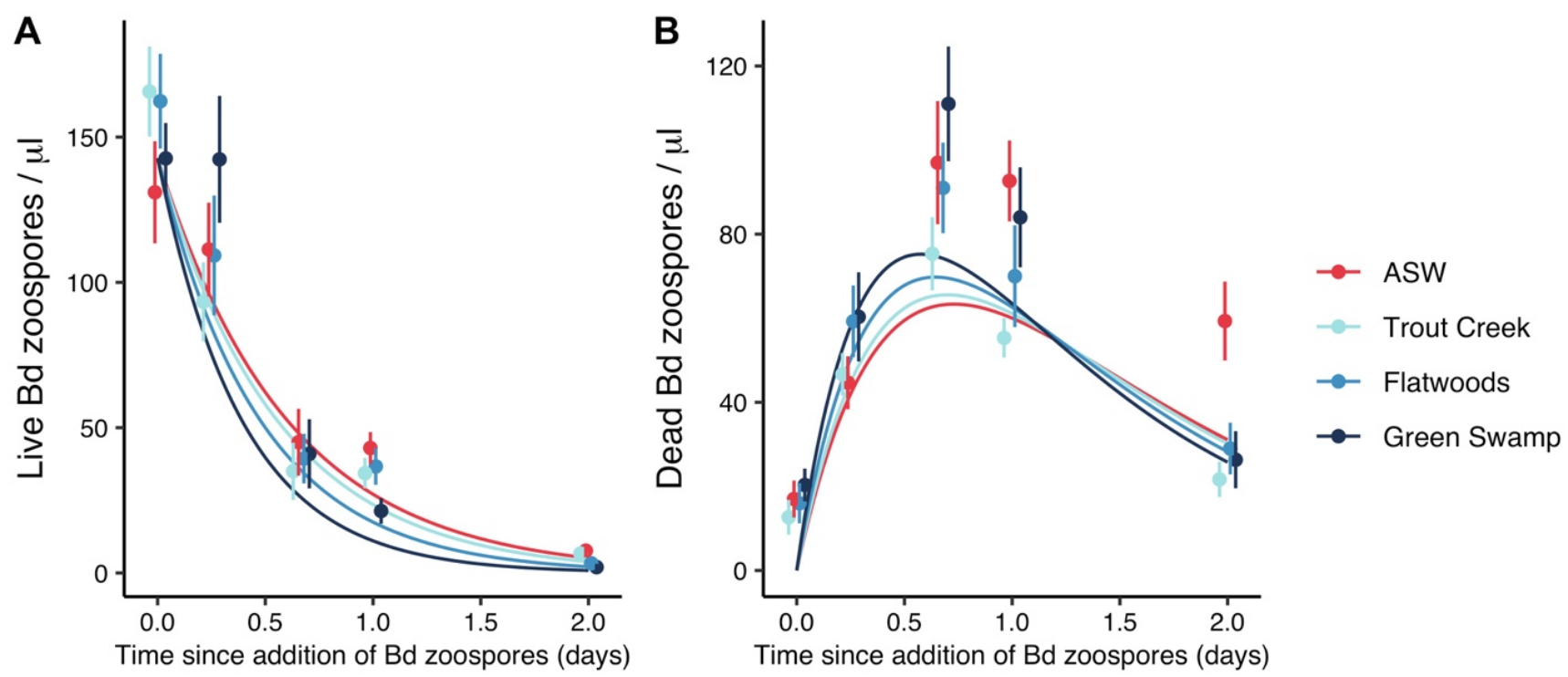


\section{Figure 4.}
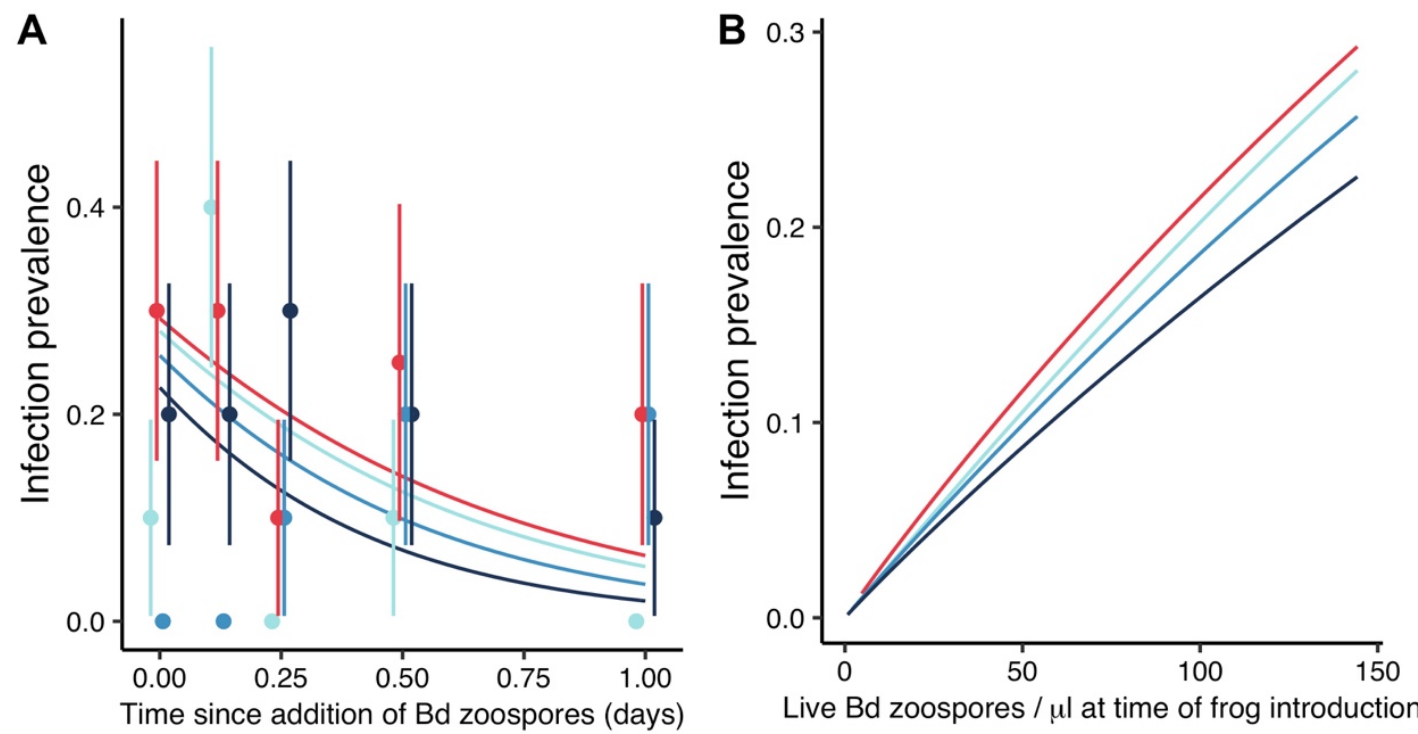

$\rightarrow$ ASW

- Trout Creek

$\rightarrow$ Flatwoods

$\longrightarrow$ Green Swamp 